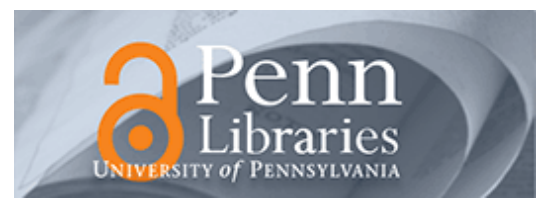

University of Pennsylvania

ScholarlyCommons

$11-2013$

\title{
Opportunities and Challenges to the Development of Healthy Children and Youth Living in Diverse Communities
}

Margaret Beale Spencer

University of Pennsylvania, marges@gse.upenn.edu

Dena Phillips Swanson

Follow this and additional works at: https://repository.upenn.edu/gse_pubs

Part of the Developmental Psychology Commons, Education Policy Commons, Personality and Social Contexts Commons, Social and Cultural Anthropology Commons, and the Social Psychology Commons

\section{Recommended Citation}

Spencer, M. B., \& Swanson, D. (2013). Opportunities and Challenges to the Development of Healthy Children and Youth Living in Diverse Communities. Development and Psychopathology, 25 (4pt2), 1551-1566. http://dx.doi.org/10.1017/S095457941300076X

Dr. Margaret Beale Spencer is an emerita professor of the University of Pennsylvania. 25th Anniversary Special Issue

This paper is posted at ScholarlyCommons. https://repository.upenn.edu/gse_pubs/266

For more information, please contact repository@pobox.upenn.edu. 


\title{
Opportunities and Challenges to the Development of Healthy Children and Youth Living in Diverse Communities
}

\author{
Abstract \\ The field of developmental psychopathology has seen growth in research focusing on interdisciplinarity \\ and normative developmental processes, including context-linked coping and adaptations. However, there \\ continues to be an uncomfortable and unarticulated perspective to view others as having culture and "the \\ self" as representing the standard. A call for explicit cultural considerations in research is needed to \\ augment the impact of these new and other significant conceptual contributions noted. Sociopolitical \\ influences on social contexts relevant to the different trajectories associated with youths' opportunities \\ and challenges are presented. We focus on macrolevel factors that frame contexts in which individual \\ development occurs. A federal and educational policy is used to illustrate how unexamined cultural \\ traditions and patterns embedded in research and policy impact development. These examples provide \\ insight in presenting issues of vulnerability, particularly for youth, and afford opportunities to present \\ advances and challenges paralleled in the developmental psychopathology field.

\section{Disciplines} \\ Developmental Psychology | Education Policy | Personality and Social Contexts | Social and Cultural \\ Anthropology | Social Psychology

\section{Comments} \\ Dr. Margaret Beale Spencer is an emerita professor of the University of Pennsylvania.
}

25th Anniversary Special Issue 


\section{Opportunities and challenges to the development of healthy children and youth living in diverse communities}

\section{MARGARET BEALE SPENCER AND DENA PHILLIPS SWANSON}

Published in:

Spencer, M., \& Swanson, D. (2013). Opportunities and challenges to the development of healthy children and youth living in diverse communities. Development \& Psychopathology, 25(4pt2), 15511566.

\section{Abstract}

The field of developmental psychopathology has seen growth in research focusing on interdisciplinarity and normative developmental processes, including context-linked coping and adaptations. However, there continues to be an uncomfortable and unarticulated perspective to view others as having culture and "the self" as representing the standard. A call for explicit cultural considerations in research is needed to augment the impact of these new and other significant conceptual contributions noted. Sociopolitical influences on social contexts relevant to the different trajectories associated with youths' opportunities and challenges are presented. We focus on macrolevel factors that frame contexts in which individual development occurs. A federal and educational policy is used to illustrate how unexamined cultural traditions and patterns embedded in research and policy impact development. These examples provide insight in presenting issues of vulnerability, particularly for youth, and afford opportunities to present advances and challenges paralleled in the developmental psychopathology field.

The critical perspective addressed in this Special Issue parallels the promises and prospects expressed by Cicchetti and Toth (2009) in the 50th anniversary volume of the Journal of Child Psychology and Psychiatry. In moving the field forward, their conceptual contribution sought to provide a framework for scientific innovations, advances, and challenges in the field of developmental psychopathology. Their conceptual strategy included reaffirming the field's interdisciplinarity and the unavoidable interplay between the domains of human development; consistent with our own emphases (see Spencer 1985, 1995, 2006, 2008; Spencer et al., 2006), biological, socioemotional, and psychological domains represent interwoven processes salient for abnormal and normal human development processes as individuals' lives unfold across time. Cicchetti and Toth (2009) specifically underscore quite salient insights afforded by a developmental analysisthat includes change and novelty, the affirmation that timing matters for behavioral organization, the possibility of multiple determinants, and the problematic assumption of invariant relations between causes and outcome. In doing so, their analysis emphasized that "since psychopathology unfolds over time in a developing organism, it is critical to adopt a developmental perspective in order to understand the processes underlying individual pathways to adaptive and maladaptive outcomes" (Sroufe, 1989, 2007, as cited in Cicchetti \& Toth, 2009, p. 16). Foundational to our perspective is their acknowledgment of the critical role of culture in both normal and abnormal development. The expansion and support of interdisciplinary research within the field, also considered normative development, is not to be understated because this type of conceptual breadth was 
previously not explored. However, cultural considerations is the one area that we view as needing augmentation, given what is often omitted or under acknowledged within the field.

A dynamic, recursive, and context-linked cultural perspective is absolutely necessary given its salience to the field of developmental psychopathology, particularly as a function of its goal to enhance our understanding of adaptive and maladaptive behavior. Moreover, we add that the integration of cultural perspectives as well as an appreciation of same for understanding life course identity processes, which are unavoidably linked with adaptation and coping in multileveled cultural contexts, remain as salient themes. For the most part and as highlighted previously (e.g., see Spencer, 2008; Spencer, Brookins, \& Allen, 1985), the contributions of culture, multiple levels of context (from a cultural perspective), and historical forces remain inadequately addressed research themes. This is particularly relevant when considered in traditional programs of developmental science research more generally and developmental psychopathology specifically, given the unfortunate but significant potential for disseminating and promulgating stereotypes and stigma.

The inclusion and integration of a cultural perspective generally provides insights and explains the "how" and "why" of humans' life course coping and adaptations to the various conditions confronted in everyday life. This approach assumes, first, that all humans have culture. Second, a foundational tenet for our perspective is that culture is ingrained in the multiple levels of context and thus is expressed as bidirectional, dynamic, and recursive relationships between adjoining levels of context. To that end, in this article we highlight the necessary perspectives required for understanding the impact of sociopolitical influences on social contexts relevant to the different trajectories associated with youths' opportunities and challenges. We begin with a focus on macro level factors that frame the contexts in which individual development occurs. The 1954 Brown v. Board of Education decision and the zero tolerance ruling represent examples of a federal and educational policy initiative that, first, illustrate sociopolitical impact on development, particularly on youth vulnerability. Second, they provide an opportunity to present advances and challenges paralleled in the developmental psychopathology field regarding multilevel research and cultural considerations. We conclude with this latter point in reexamining current research practices and offering directions for future research.

Macro- and Exolevel Factors: Framing Developmental Contexts

Using Bronfenbrenner and Ann C. Crouter's (1983) conceptualization as well as insights from James Garbarino (1979) and ecological psychologists have jointly made significant contributions to the current appreciation of context. Particularly Bronfenbrenner's (2005) delineation of and attention to the embedded micro-, meso-, exo-, and macrolevels of the ecology situated in the chronological level of the ecosystem have been an influential force. The most intimate and proximal is the microsystem, representing the immediate environment, including home and school, where youths have direct, personal interactions. The four levels are intensely intertwined. The mesosystem refers to the interactions that occur between levels. The exosystem refers to the individual's community at the neighborhood or school level. The macrosystem refers to the society at the most general level, including culture, political systems, and laws that represent expected societal norms. Although increasing conceptual complexity, the context-linked perspective has enhanced our appreciation of the social 
sciences more generally and developmental science specifically; nonetheless, its actual and meaningful integration into the design of research agendas and their interpretations still begs refinement. For example, the cultural traditions at the exosystem, or the level of context in which an individual or group may generally lack firsthand experience, have implications for the satisfaction of developmental tasks attempted at the microsystem level (see Bronfenbrenner, 2005; Bronfenbrenner \& Crouter, 1983). Similarly, the design and conduct of developmental science determined the exolevel of the context is adversely impacted by assumptions at the macrolevel; it is also potentially undermined by the lack of authentic and accurate knowledge about diverse humans and their social connections at the micro- and mesolevels of individuals' social and physical ecologies.

More specifically, the macrolevel communicated attitudes, values, beliefs, and assumptions about "unfamiliar others," communicated recursively between the macro- and exolevels of the ecology, are unavoidably significant influences for developmental science (e.g., the research questions asked and the design decisions made). As suggested, the dynamic and recursive associations between levels of the ecology have profound implications for the ultimate developmental science determined social, educational, and health policies frequently implemented through mesosystem "supports" for those coping and adapting to diverse contextual conditions at the microlevel. It is not surprising then that too many developmental science informed "supports," as derived from unacknowledged culture and context-linked systems, may fail to be experienced as micro- and mesolevel resources or to be experienced as supportive at all (see Spencer 2008; Spencer, Swanson, \& Edwards, 2010). By failing to include the ways in which cultural traditions (i.e., including unacknowledged biased assumptions) impugn and confuse our ways of thinking about and implementing developmental and psychopathology science, opportunities are missed. The conceptual shortcoming virtually guarantees a continuing pattern of life course disparities.

For any given moment in time as influenced by events that preceded it, the macrosystem level communicated and disseminated cultural attitudes and beliefs concerning power, fairness, and justice prevail and represent the context of development for all humans. However, such themes are generally absent from consideration in the scientific literature as contextual features. Adolescents' challenges of authority and rules as part of their normative development is frequently unquestioned in general, yet perceptions regarding Black males' parallel behavior that challenge or question authority are viewed as threatening. Their expectation of having a right to be in public spaces without harassment is not explored as contextually salient to their adaptive patterns. Unacknowledged is that risk factors for particular individuals may, alternatively, function as protective factors for others. The exception might be infrequent, and nonempirical references to "White privilege" or "whiteness protective factors" although specific and relevant variables, are seldom actually reported in the list of constructs assessed and empirically included in programs of research. For the current 21st-century period given the conceptual innovations alluded to by Cicchetti and Toth (2009), it continues to be difficult to count studies that acknowledge the diversity of the sample population except by gender, income status, and age. This is probably due to the continuing befuddlement concerning what constitutes authentic or balanced comparisons; that is, more often than not, White middle-income youngsters are compared against dark, lower income samples without acknowledging the flawed research design. Middle-income 
minority children are seldom included in large- or small-scale studies, and poor and working-class White families are equally invisible.

Nevertheless, the noted 50th anniversary publication and perspective quite optimistically and generously suggested that cultural themes in the conduct of developmental science Opportunities and challenges 1553 had reached and facilitated a paradigmatic shift (see Cicchetti \& Toth, 2009, p. 21). However, as reported a quarter century earlier, our view at that time alternatively suggested a call for a paradigmatic shift as opposed to the successful achievement of it (see Epps, 1985; Spencer et al., 1985). Our contemporary conclusion remains the same in that a shift is needed. That is, counter to our colleagues' optimism, an accomplished and meaningful paradigmatic shift has yet to be achieved.

Our perspective presses for theoretical changes both within disciplines and across disciplinary lines. Although our entreaty for reflection is, at minimum, as equally complex as the cautions forwarded by Cicchetti and Toth (2009), given unresolved philosophical and historical themes, our petition for conceptual innovations and inclusiveness represents parallel optimism nonetheless.

The perspective forwarded foments and describes the multitiered benefits of the valuing and embracing of an identity centered, context-linked, and culture-acknowledging developmental perspective about normal and abnormal coping and adaptation. The perspective is particularly enjoined for acknowledgment when considering the basic human development of youths growing up in ethnically diverse communities or those saddled with unacknowledged stigmatizing contexts. That is, independent of whether the behavioral adaptations suggest developmental psychopathology, the core features indicated are important and require careful analysis before diagnosing and further labeling. Thus, identity features, the contributions of context, and the implications of historical circumstances and cultural traditions for contemporary coping and adaptations require careful analysis.

For minorities and extremely impoverished young people, the persistent and long-term trend has been an a priori practice to assume unhealthy adaptations or psychopathology (see Allen, Spencer, \& Brookins, 1985; Franklin, 1985; Slaughter \& McWorter, 1985; Spencer, 2006, 2008; Spencer et al., 2006). This penchant is different from the approach taken when studying White, middle-income, and male youth. That is, as opposed to acknowledging historical context (e.g., see Elder, 1998), contextual situation (e.g., see Bronfenbrenner, 2005; Bronfenbrenner \& Crouter, 1983), cognition-linked psychosocial processes as described by Erikson (1968), and adaptation processes (e.g., see Anthony, 1974), the approach taken for devalued youngsters and stigmatized young people is different. The conceptual complexity noted for Whites and interdisciplinary research trajectories indicated are obfuscated by "theoretical blinders." Poor youths and those from ethnic families of color are assumed to show a generalized "underdevelopment" (see Gordon Gordon, 1994). That is, as opposed to understanding youths' unfolding human development and coping patterns in response to particular contextual evaluative features ("driving while Black," and now "walking while Black") or inferred stereotypes (e.g., teacher stereotypes about and fearfulness of dark-skinned persons or male students specifically), youths' dissonance imbued adaptations may be characterized in psychopathological ways. As a consequence, our suggested developmental science approach to development and psychopathology suggests important differences. It explicitly considers and integrates the impact of 
race, ethnicity, color, and national origin as underlying and core historical influences, which have implications for contemporary coping and diagnoses and are consistent with Cicchetti and Toth's (2009) key points concerning cultural considerations (p. 23).

The suggested knowledge base needed for conceptual shifts is due to several historical observations. A critical one is that Western-practiced developmental science lacks the impetus needed for amore informed approach to developmental psychopathology. More precisely, there are two fairly recent illustrations of individuals held accountable for their actions by their respective societies, thus explicitly capturing macrolevel expectations of humane behaviors: the mid-20th century Nuremberg Tribunals regarding the treatment of Jews and the publicly acknowledged Truth and Reconciliation Hearings at the end of the 20th century regarding the oppressive experiences of Black South Africans. The United States has never had to engage in self-examination and critique in so public a manner. That is, individual behavior can be hidden behind public documents without individual responsibility for behavior and decision making. Abraham Lincoln's Emancipation Proclamation, of which we recently celebrated the 150th anniversary, and the 1954 Brown v. Board of Education legislation were designed to publicly address dehumanizing and marginalizing practices in the United States. However, they did not engage in "supportive interventions" with citizens who viewed the ending of slavery and the policy of integration as corruptions of White schools and ways of life. Consequent policies and supports have never been leveled at those making decisions about others' daily lives, levels of risk exaggerated, and social traditions conceptualized and designed to deny fair access to resources and opportunities. Although there are many youths whose experiences remain shaped by denied access, there are numerous examples of resiliency and positive coping and adaptations.

Although frequently overlooked as an important fact of life, many youths do succeed despite living in socially designed, support-compromising and highly vulnerable conditions. Cultural traditions emanate from everyday practices designed to cope with the conditions described. At the same time, the outcomes and developmental processes of numerous others, particularly racial and ethnic minority adolescents and poor youth, manifest the challenging situations noted; thus, youths represented by behavioral problems, learning disability diagnoses, significant school dropout rates, and disproportionate representation in juvenile justice systems often lack access to developmentally sound, culturally sensitive, and responsive supportive programming options. These trajectories, although individually experienced, are shaped by macro- and exolevel factors.

Sociopolitical Influences on Development

Our approach acknowledges multiple influences on developmental processes and outcomes including (a) contributions of 1554 M. B. Spencer and D. P. Swanson the social and traditional media influences; (b) disseminated views concerning earned status, albeit a narrowed or incomplete focus on disproportionate access to resources for enhanced strengths for some (i.e., a privileged status) and simultaneously a heightened focus on risk factors and untoward outcomes for others(i.e., assumptions of "self-determinative" disadvantage); and (c) the patterned tradition of not acknowledging the group's endogenous strengths, accessed protective factors, or exogenous sourced and earned supports. Unacknowledged relational complexities and social tensions in and out of the developmental science 
community and social science arena more broadly contribute to the continued silencing of the dilemma and theoretical shortcomings (i.e., a virtual conceptual and social conundrum).

As an example of historical and social-cultural influence, unprecedented advances in communication technology made President Obama's first election and global reactions to it instantly observable to a technologically linked "global community." The instant global reaction to Mr. Obama's ascendancy to the nation's highest office also highlighted the election of America's first president who is African American. His status as an American of color resonated around the globe and was recognized as a special and unexpected feat. An oft-repeated comment was disbelief that one had actually lived to see an African American elected to this nation's highest office. President Obama's election as the nation's 43rd president, for some, also suggested a change in the social fabric of the United States: the assumption of a postracial America. Consistent with that perspective, the liberal strategy has been to remain silent about the continuing salience of color in America's social discourse. Thus, for those preferring to diminish the significance of identifiability and the specific contributions of color, race, ethnicity, gender membership, and immigration status for level of vulnerability and privilege, the election results held special meaning. That is, for those wishing to ignore disproportionality regarding the accessibility to broad and relevant supports as well as particular individuals' exposure to significant challenges, the election outcome heralded a particular message. It encouraged the view that color and social status no longer mattered in 21st-century America.

At the same time, media depictions having to do with adolescents' experiences are too frequently negative. Unfortunately, negative media depictions of youths too often frame news reports without concomitant acknowledgment of the rapid changes and unique and additional challenges that accompany some youths' coping efforts to prepare for adulthood status (Howe \& Strauss, 2000). The scenario represents the quandary experienced by adolescents independent of vulnerability status (i.e., those having significant and accessible resources and supports as well as those disproportionately burdened by excessive challenges).

Social factors and resistant forces

Identity development does not happen in a void; instead, it is influenced by an individual's environment at every level. To articulate how the ecological mechanisms explained by Bronfenbrenner (2005) are realized in identity development, Spencer's $(1995,2006,2008)$ phenomenological variant of ecological systems theory (PVEST) provides a unique, context and culturally inclusive strategy; as such, it represents an identity focused cultural ecological perspective. The framework focuses on individuals' perceptions of their environment as important meaning-making factors to consider when examining issues such as neighborhood safety or educational policy decisions. For example, regardless of the intent of Brown v. Board of Education in 1954, students' perceptions of school desegregation and the impact on their daily interactions are what most significantly influence their identity development.

Most important about the dynamic and recursive conceptual strategy, PVEST articulates the ways in which perception impacts development and how normative development processes unavoidably influence ways of seeing or meaning making. Every individual has a unique balance of supports and 
challenges, the combination of which determines his or her net vulnerability. When faced with stressors and challenges that accompany daily life events and normative developmental tasks(see Havighurst, 1953), individuals cope in ways that are either immediately adaptive or maladaptive. If responses by others are positive and the coping mechanism proves effective, the individual will likely continue to employ the chosen strategy. Over time, that coping mechanism will become part of an emerging identity. In some cases, behaviors that are adaptive in the short term may be maladaptive or less positive as judged in the long term. For example, hypermasculine (i.e., exaggerated sex role) behavior may keep an adolescent male safe or earn him respect in a dangerous neighborhood; however, if the same behaviors are employed too frequently over time, they may have serious negative consequences as inferred by socializing adults (Spencer, Fegley, Harpalani, \& Seaton, 2004). Supports must be introduced along the way to teach adaptive coping mechanisms and to help youths receive positive feedback that will allow them to internalize the coping behavioral adaptations and externalize them in myriad settings regardless of the context character.

In addition to factors in the immediate environment, individuals' location in time can also play a critical role in identity development. The impact of an event is largely determined by the developmental period in which it occurs (Elder, 1998). A longitudinal study of individuals who lived through the Great Depression found that individuals who were born in the late 1920s were more adversely affected than were children born earlier in the decade. Although both groups lived through the Great Depression, the latter group spent their early childhood during a relatively stable economic period. Both the impact of a historical event and the relationship between the event and the individual's developmental period are important to keep in mind when considering the significance and impact of macro- and exosystem level events like the Brown v. Board of Education decision, zero tolerance policies toward the end of the 20th century, and No Child Left Opportunities and challenges 1555 Behind, which impacted schooling at the turn of the 21st century. All are policies that continue to specifically shape school experiences.

Sociopolitical forces: Brown v. Board of Education.

Spencer, Tinsley, Dupree, and Fegley (2012) relate the undergirding themes of vulnerability with the ultimate inadequacy of the Brown v. Board of Education (1954) ruling. Specifically, when considering the Court's deliberation, only risks were acknowledged, as opposed to an appreciation of the Black community's strengths and protective factors as well. For changing the outcome of the subsequent legislation, the Supreme Court's decision might have enjoyed a greater impact and been beneficial by recognizing human vulnerability for Americans more generally. That is, acknowledging a perspective of the multiple sources of vulnerability for Blacks as well as Whites would have suggested the policy efficacy of considering different supports for each (i.e., thus enhancing the potential for making a positive difference). Stated differently, the remedies proposed by the Court might have been customized for encouraging the same outcomes for all citizens (i.e., achieved resiliency at the individual and group levels; relational or intergroup successes in regard to equity and justice; and the patterned, long-term acquisition of a good education for all citizens) even if varied strategies for accomplishing these outcomes would have required both thoughtful identification and unique strategies of implementation. For example, for particular Whites, facilitating good outcomes as resiliency goals might 
have included strategies for resisting both their stereotypic a priori views of African Americans and their unaddressed and patterned views of White superiority.

Spencer et al. (2012) further suggest that strategies for obtaining resiliency might have included galvanizing and sustaining the group's love of education, knowledge, and the interconnectedness of family and fictive kin irrespective of the multiple and often silenced forms of oppression, bias, and negative imagery confronted (see Spencer, Cross, Harpalani, \& Goss, 2003). The potential lesson learned and implemented through the writing of the 1954 Brown v. Board of Education decision would have acknowledged that each group (i.e., Blacks and Whites) confronts different risks and thus would require customized support for obtaining the desired outcomes for all citizens of the United States of America. Thus, the actual supports designed for and accessible by each group, given varying confronted risks, would need to be different and customized for obtaining successful outcomes given the same legislation and its inherent societal goals.

Unfortunately and without question, that view was not apparent given the insights provided by neither judicial consultants nor research findings presented to the Court when Brown v. Board of Education was argued. Alternative and unfailing in similarities to historical perspectives, the conceptual traditions, practices, and research assumptions presented Blacks as possessing mainly risk factors; at the same time, Whites continued to be associated singularly with innate strengths (i.e., inherent and significant protective factors absent risks and challenges).

Sociopolitical forces: Zero tolerance.

Henault (2001) describes zero tolerance as a set of policies that dictate a penalty for any infraction of an established rule that contributes to "intolerable," yet equitable, treatment of all violations. The zero tolerance policy was created for the purpose of serving the public good, but similar to the Brown v. Board of Education 1954 decision, the outcomes related to its application in school practice have been less than favorable. People, context, and history have shaped how this policy has been utilized. The policy proved detrimental to the educational and life outcomes of minority youths participating as students in urban school settings.

The concept of zero tolerance originated from state and federal policies that were enacted in the 1970s and 1980s to combat drug trafficking and support drug enforcement efforts (Morrison et al., 2001). In the late 1980 s to early 1990 s the idea of zero tolerance became of interest to the school community as a way of ensuring safety and reducing school violence. The scope of the practice moved beyond just handling the issue of illegal drugs and expanded to include aggressive behavior that led to school discord (Skiba \& Peterson, 1999). Models of zero tolerance practice are varied, but they do possess some general characteristics. Schools adopting a rigid orientation to zero tolerance maintain a very reactive stance when addressing issues of safety.

These practices are consistently counterproductive to the healthy development and achievement of students (Morrison et al., 2001). The American Psychological Association (APA) Zero Tolerance Task Force (2008) conducted an evaluative study of the impact of zero tolerance practice. The evaluation, which included an assessment of its developmental appropriateness, found a lack of congruency 
between psychosocial development and the use of zero tolerance. This study and others note that children and youth are simply not mentally mature enough to understand the concept or consequences of the practices (Gregory, Cornell, \& Fan, 2011). School structure, staff perceptions, and school policies often conflict with the normative developmental needs and inference-making processes of youths (Acosta, Weist, Lopez, Shafer, \& Pizarro, 2004; APA Zero Tolerance Task Force, 2008). For example, the need to develop positive affiliations with others or to question the status quo (i.e., challenge authority) could lead to removal from class, suspension, or expulsion (Michail, 2013; Vavrus \& Cole, 2002).

Many students subjected to school discipline have a history of academic and behavior problems that become compounded and increase their risk for poor outcomes. Removal from the school contexts creates discontinuity in the learning process that makes learning and overall development more challenging (Advancement Project and Civil Rights Project at Harvard University, 2000; Morrison et al., 2001; Wallace, Goodkind, Wallace, \& Bachman, 2008; Ward, 1995). Zero 1556 M. B. Spencer and D. P. Swanson tolerance practices generally provide no opportunity for youths to learn and be supported in appropriate behaviors; removal from classrooms and expulsion can exacerbate continued problem behavior (Chin, Dowdy, Jimerson, \& Rime, 2012; Fenning et al., 2012; Sharkey \& Fenning, 2012). Children and youth classified as needing special education are particularly vulnerable to negative outcomes associated with zero tolerance because they are typically identified as those most often suspended or expelled from school (Chin et al., 2012). Specific references in the literature identify higher rates of academic disengagement by youths with poor role models, problem behaviors, and difficulty with reentry into the school system (Casella 2003; Michail, 2013; Noguera, 2003; Skiba, Peterson, Boone, \& Fontanini, 2000).

There is the cumulative effect of negative stigmas resulting from being suspended or expelled and identified as a special education student. Black males represent a large majority of the students who are identified as special education and are often susceptible to punitive measures under zero tolerance (Advancement Project, 2010; Fenning \& Rose, 2007; Noguera, 2003; Raffaele Mendez \& Knoff, 2003). Student removal, suspension, or expulsion resulting from a zero tolerance policy triggers a series of negative emotions in children and youths, which is compounded among those in marginalized groups. Feelings range from anger and sadness to frustration and shame (Schulz \& Rubel, 2011). Youths are not encouraged but instead encounter compromises to their self-esteem and relationships with peers and teachers. Some youths, for lack of other alternative supports, engage in "antisocial" or maladaptive behavior (Michail, 2013; Schulz \& Rubel, 2011). This occurrence ties in to discourse related to the dissonance youths experience within the context of the school that undermines development (Phelan, Davidson, \& Cao, 1991).

Given the resources and support youths have at home, removal from school for behavior can exacerbate existing conditions of stress. The difficult relationships school personnel have had with youths and their parents who are living in poverty are well documented (see Swanson, Spencer, Dell'Angelo, Harpalani, \& Spencer, 2002). Depending on parental perception, expectations, and experience with a school, a youth could be either supported in changing the behavior that resulted in his removal from school or further marginalized (Chin et al., 2012). In addition, Michail (2013) notes that "disadvantaged communities" and 
families may be stressed with other complex needs that would negate support to youths who are removed from school (p. 159).

The zero tolerance policy alienates students, their families, and the communities in which they live (APA Zero Tolerance Task Force, 2008; Michail, 2013; Schulz \& Rubel, 2011). This is a common pattern observed in under resourced urban communities, and it poses serious implications for potential vulnerable populations. Research indicates that African American children are suspended at higher rates, experience less success in graduating from school, and have higher juvenile and incarceration rates, contributing to a trajectory referenced as the "school to prison pipeline" (Advancement Project, 2010; Casella, 2003; Lewis, Butler, Bonner, Fred, \& Joubert, 2010; Morris, 2012; Sharkey \& Fenning, 2012; Tobin, Sugai, \& Colvin, 1996; Wallace et al., 2008). The communities in which highly vulnerable youths reside are also stereotyped, and the negative stereotypes influence the level of service, support, and relationships with the school.

Zero tolerance is but one approach to addressing matters of safety and discipline. As a punitive approach, it typically does not account for the contextual factors in which students are situated, and assumes blame and assigns punishment regardless of the circumstances or type of infraction (Michail, 2013). Other approaches to safety and discipline inculcate academic components, therapy, or some combination within a larger school model. Approaches that are leveraged depend on the school's understanding or perspective of the source of the behavioral issue (Day-Vines \& Day-Hairston, 2005; Michail, 2013; Skiba et al., 2000). Academic approaches are selected based on the belief that there is a developmental issue impairing a student's ability.

The academic approach was historically ill positioned to address the contextual disadvantages impacting student behavior and achievement. In contrast, therapy-based approaches were more conducive to exploring and integrating contextual factors that afford the student an opportunity to process feelings, problem solve, and develop action plans to address the issue (Chin et al., 2012; Fenning et al., 2012; Michail, 2013; Sharkey \& Fenning, 2012). In an integrative strategy that utilizes academic and therapybased approaches within a developmental orientation, a student's need for validation and support facilitates the shift toward more favorable outcomes. Integrated approaches leveraging strategies that can be used in the various contexts that vulnerable children and youth navigate offer the most promising results. Schools using this integrated approach are more responsive and informed about the needs of students and their families (Boccanfuso \& Kuhfeld, 2011; Bronwyn \& Luthar, 2002; Michail, 2013; Van Acker, 2007). Overall the findings mirror the review by Spencer and JonesWalker (2004), which indicates that effective approaches are more often associated with theoretically informed programming.

Sociopolitical forces: A critical race perspective

We incorporate differentiated insights about how the impact of macro-, exo-, meso-, and microlevel supports and challenges are integrated and considered. Unfortunately, social science emphases do not consider how diverse people live, frame, incorporate, and adopt cultural patterns of resistance to 
challenges regularly confronted as part of their daily lives. Further, few efforts explore how communities make meaning of their situations as America's Black, Yellow, White, and Brown citizens.

Each noted group continues to represent uneven access to resources and the attendant crossgenerational economic Opportunities and challenges status and social situations associated with that status. The impact for the experiences had during periods of heightened vulnerability such as adolescence and emerging adulthood continue to exist but are virtually absent from the consciousness of developmental science. Our assumption is that the shortcoming contributes to inadequate policy, indefensible programming, and teacher training traditions, and thus "unintended systems injury" (Spencer, 2008; Spencer et al., 2012). At the same time and as reported elsewhere (e.g., see Spencer et al., 2003), previously demonstrated successful strategies are ignored or made invisible. The penchant and failure to recognize, access, and make use of successful supportive strategies are not only missed opportunities and an apparent dependence on stereotypes but also suggest contributions to a status of "motivated forgetfulness," at best.

Inconsistent with a critical race perspective, legal decisions based on stereotypical generalizations may "subvert the criminal justice system's promise that each individual defendant will be tried according to the specific facts of his case" (Armour, 2000, p. 187). Such decisions merely further enhance and engrain racial stereotypes in our society and create an atmosphere where Blacks avoid public places, not wanting to be mistaken for an assailant (i.e., as recently illustrated by the killing of a youth viewed as menacing while walking through a gated community). Thus, legally justified use of racial stereotypes serves to limit the ability of people of color to be active agents in their own lives; this not only restrains the spatial configuration of their engagement but also limits the range of their emotional engagement by instituting self-surveillance but, as suggested by Stevenson's (1997) theorizing on youth anger, as internalized stress further compromises physical and mental health.

Butler (2000) employs critical race theory in his development of the concept of "jury nullification ... [which] occurs when a jury acquits a defendant who it believes is guilty of the crime charged" (p. 195). Butler contends that it is the moral responsibility of Black jurors to emancipate certain nonviolent guilty Blacks, owing to the fact that the system itself is biased. Black communities should not lose their members to a jail system in a society that has promoted Black antisocial activities through institutional racism. The Black prisoner is simply implicated in a system that has been set up by the status quo (individuals who do not have Blacks' best interests in mind). An important perspective is that the law uses punishment of individuals to deal with social problems that are the result of ingrained racism in society. Butler continues to argue that no general legal principle leads to justice in every case. Legal principles are also based on socially constructed assumptions, and sometimes these assumptions lead to inequitable racist outcomes. Hence, it is the moral responsibility of jurors to acquit guilty individuals based on the existence of unjust laws. The underlying assumption is that the greater good of the Black community should be considered in nonviolent cases.

Derrick Bell (2000) looks at the outcomes of integration mandates and asks a key question: Is racial balance in the schools enough to provide educational equity? Bell contends that, since the 1930s, the historical approach of the National Association for the Advancement of Colored People has been to 
eliminate racial segregation across society. This approach took precedence in the education system, particularly, with the passing of Brown in 1954. The subsequent lack of compliance with the legal precedent set by Brown v. Board of Education led to a series of school litigation cases being filed. Bell explores the diverse expectations of the prosecuting lawyers and the clients they served. He establishes the ways in which their views on educational equity and approaches to change diverged.

The theory behind the integration approach is that "equal educational opportunity" can only be achieved when Black students have access to the resources of White schools and that only through integration can Black students receive the same education. However, Bell (2000) claims that this theory does not consider the effects of continued racism in society. From the human vulnerability perspective offered by Spencer and colleagues, regarding unequal risks and access to protective factors as supports, Brown v. Board of Education and the National Association for the Advancement of Colored People do not sufficiently address "state-supported subordination of Blacks in every aspect of the educational process" (Bell, 2000, p. 240). Racial separation is only the most obvious expression of racism in the educational system. Even after integration, Black children frequently have lower academic performance and a higher expulsion rate. In addition, integration has been achieved only in smaller districts. Large urban areas have not been touched by the policy because these areas are frequently so drastically segregated that entire districts are racially separate entities. Bell (2000) maintains that alternatives to integration need to be imagined and implemented. He further asserts that enforcement is needed that pairs educational content and process with the constitutional rights given by Brown. There is no question that a vast majority of urban schools are racially homogeneous. However, from a shared human vulnerability perspective relevant to all citizens, youths' efforts to learn in contexts with undereducated, inadequately trained, and professionally underdeveloped teachers introduce persistent sources of unacknowledged risk. Worse yet, tax paid teachers who should be viewed as resources represent traditions, which may not be experienced by some youths as sources of support. At the same time, teachers of students with whom they share stereotypes (i.e., in the "othering" of underserved students) learn to believe that achievement gap findings represent an earned superior achievement status. Such youths' enjoyment of privilege further contributes to inauthentic identity statuses and, unavoidably, feeds into the intergenerational perpetuation of stereotypes.

Johnson (2000) cites United States v. Fordice (1992), which found discrimination in Mississippi's postsecondary educational system but rejected African American plaintiffs' requests to obtain equal funding for Mississippi's publicly funded historically Black colleges. Rather, under United States v. Fordice, these colleges are merged into Mississippi's White college system under integration. Johnson argues that abolishing separate historically Black colleges should not be considered advancement and that Black students should have a choice about what type of college to attend. In essence and consistent with Spencer's PVEST theorizing, young people should have a choice of what they consider phenomenologically as perceived and experienced support (see Spencer 1995, 2006, 2008). Johnson's review maintains that many Black students prefer all-Black colleges as immersion experiences rather than attendance in predominately White contexts, which are frequently perceived as representing a hostile environment to Black students (see Chestang, 1972). 
W. E. B. Du Bois clearly characterized the educational dilemma for our society in 1935, and his concerns remain prevalent even today. Integration has not proved to be the silver bullet for educational equity in our society, as predicted by Du Bois, and more comprehensive changes need to be made in society before educational equity can be a reality. Du Bois (1935) states (quoted in Bell, 2000, p. 243):

"[T] he Negro needs neither segregated schools nor mixed schools. What he needs is Education. What he must remember is that there is no magic, either in mixed schools or segregated schools. A mixed school with poor and unsympathetic teachers, with hostile public opinion, and no teaching of truth concerning black folk, is bad. A segregated school with ignorant placeholders, inadequate equipment, poor salaries, and wretched housing is equally bad. Other things being equal, the mixed school isthe broader, more natural basis for the education of all youth. It gives wider contacts; it inspires greater self-confidence; and suppresses the inferiority complex. But other things seldom are equal, and in that case, Sympathy, Knowledge, and the Truth, outweigh all that the mixed school can offer."

Marable (1995) draws upon Du Bois' general argument as he articulates the two camps in the controversy of how to actualize racial equality. Marable maintains that in alignment with Du Bois, one camp argues that Black culture and institutions in society should be maintained and that equality does not come from assimilation. Following Du Bois' concept of double consciousness, Black Americans live with a double sense of how to function in American society, and equity does not ensue from the erasure of Black knowledge (see Du Bois, 1903). The other camp, including Civil Rights activists, tends to perceive equality as inclusion, which stems from a society that is "color blind." A critique in alignment with Du Bois would maintain that we have not reached the point in American society where a colorblind culture is possible, despite the end of legal segregation. Racism is real and evident through structural inequities and White privilege.

Marable (1995), as a critical race theorist, criticizes affirmative action as too conservative as he maintains that affirmative action "sought to increase representative numbers of minorities and women within the existing structure and arrangements of power, rather than challenging or redefining the institutions of authority and privilege.... [A]ffirmative action was always more concerned with advancing remedial remedies for unequal racial outcomes than with uprooting racism as a system of white power" (p. 87). Affirmative action quotas have resulted in the growth of the Black middle class but have not restructured the ways in which systems continue to define and perpetuate racism. Delgado (2009) is sympathetic to Marable's argument as he asserts multiple reasons why many scholars of color are critical of affirmative action. He maintainsthat inclusion of people in society through affirmative action is based on social utility and that the discourse does not consider reparations or rights.

Affirmative action is a stabilizing device and a system of social control and balance in American society. Delgado criticizes the ways in which the stamp of affirmative action is stigmatizing and ahistorical. It ignores the ways in which White men have benefited from their own affirmative action programs for hundreds of years since the inception of this country. Under affirmative action, Black individuals are expected to be assimilationist, to serve as role models to uplift an entire people, examples to justify the myth that those who work hard will succeed. Those expectations are not burdens carried by Whites against whom Blacks are compared. 
In addition, Delgado (2009) maintains that fairness requires reallocation, and this is not the way in which affirmative action is framed. He maintains that

"by labeling problematic, troublesome, ethnically agonizing a paltry system that helps a few of us get ahead, critics neatly take our eyes off the system of arrangements that brought and maintained them in power, and enabled them to develop the rules and standards of quality and merit that now exclude us, make us appear unworthy, dependent (naturally) on affirmative action. (p. 398)"

Despite the "advancements" from affirmative action, general statistics indicate that inequity and racism continue to be prevalent and debilitating to our society particularly when examining achievement outcomes. They represent sources of support and privilege while orchestrating experiences of risk and challenge for others; given the latter, awareness of the many unacknowledged sources of inequality may have implications for youths' coping. Behavioral adaptations may be intended as protective (e.g., reactive disengagement from hostile learning environments); however, in the long term, the coping patterns evoked may function as additional sources of challenge to psychological well-being versus providing developmental assets and supports. The contextual dissonance that evokes the patterns noted (i.e., lack of individual-context fit) are not frequently integrated into research strategies nor considered in the interpretation of findings including programming outcomes.

Vulnerability: Diverse Developmental Periods, Needs, and Expressions

Consistent with all stages of the life course, adolescence unfolds in contexts influenced by the particular historical moment, physical place, social-cultural traditions, and distinct interactions among them. As part of their efforts to attain adulthood status, adolescents strive to attain progressively Opportunities and challenges 1559 abstract academic and career linked competencies as well as social-emotional relevant relationship skills. Their efforts may occur in generally under acknowledged and broadly diverse contexts relative to support level; as suggested in the case of minority youth, there are numerous examples of a lack of fit between an individual's demographics and phenotype (e.g., gender and skin color) and context character. Nonetheless, universal expectations for youth outcomes and myriad competencies are broadly disseminated by media, which also aid their reinforcement and maintenance. Thus, the socially constructed and historically linked variations in support level are frequently overlooked or not recognized in media portrayals of "difference or gap outcomes" (i.e., social portrayals) more generally. The absence of authentic ways of examining social indicators such as color, race, ethnicity, and socioeconomic variations (combinations of these as well as their structural supports) is alarming. These categories' association with the statuses of privilege and insufficiency is intrinsically alarming and informing. A long-standing association with ego processes has been the norm with continuing assumptions that (positive) mental health for minorities suggests unrealistic self-processes. Theoretical analyses that explore meaning making and unavoidable cognitive processes and stress sensitive biological changes (e.g., neurophysiology of stress and learning) are ignored even when introduced.

In many ways over the last several decades, we've tried to articulate the position and emphasize the premise of universal human vulnerability (i.e., that all humans both confront risks and benefit from 
protective factors of one sort or another as each individual navigates the world; see Spencer 2006, 2008; Spencer, 2012). This view posits the basic assumption that human vulnerability does not reflect most traditional research perspectives but instead situates privilege (including generally unacknowledged benefits) as the status of all Americans; thus, competition, opportunities, and advancements are seen as equally accessible to all. Given the view's lack of credibility and authenticity for particular citizens (i.e., especially those of color and/or highly impoverished individuals), the assumption of equal access promotes the conclusion that disproportionality or failure for some and the patterned successes for others are legitimate achievement or group status outcomes. That is, some of a society's citizens, as success stories, are made to be viewed as the norm. Individuals' disproportionate access to protective factors and supports (i.e., enjoyed without full acknowledgment of them) is seldom noted. Mclntosh (1989) has designated the frequent (but unarticulated) association of support with high status as a "knapsack of benefits and privileges"; as indicated, the situation is inconsistently or infrequently associated with the rampant tension of identifiability and ethnicity-linked negative stereotypes and treatment. Of particular importance, the dilemma associated with the latter multiplies the problem of patterned adversity owing to significant challenges made "ordinary" as a life course experience. More troubling, assumptions concerning legitimate conditions of meritocracy accompanied by assumed investments of labor, hard work, and intrinsic motivation believed expended actually reinforce a condition of privilege as "norm level" given an assumed level of effort invested by particular individuals. For others, widening outcome gaps reinforce stereotypes of laziness, lack of motivation, and intellectual deficits assumed to represent native capacities for the group as a whole.

Different from these views, a conceptual commitment to the universality of human vulnerability and its dual contributors as protective factors and risks allows for greater exploration of the "how" of outcomes and not just the "what" as a developmental specific outcome. The suggested alternative framing connects, in a virtual fulcrum-balancing manner, myriad character o frisks as pitted against individuals' diverse strengths as protective factors, thus affording particular levels of supports and protection. The afforded and nuanced analysis proffered makes explicit both culturally specific and shared protective factors, strengths, and supports (e.g., whiteness stereotypes as the norm, religious beliefs, socially connectedness, spirituality, faith traditions, cultural socialization practices, and social connectedness). A group's exaggerated high vulnerability owing to significant risks (e.g., reversed policy impact, low school achievement, and inadequate health resources) are emphasized rather than the tradition, which is to ignore their existence and experience (see Spencer et al., 2012).

As suggested by Spencer et al. (2012), there is a minimum of two strategies for interpreting standards upon which programs of research are implemented and findings interpreted. One considers primarily protective factors for certain youths and groups; in parallel fashion, other youths' strengths are viewed to be basically inferior or invisible. The latter group of young people are represented in the literature as possessing primarily and narrowly risky factors without acknowledging their availability of protective factors (e.g., both as familial and group traditions and shared strengths). This short-sighted perspective is associated with assumptions of meritocracy for some as well as presumptions that high-risk status individuals are devoid of strengths and supports. Represented by a variant of PVEST theorizing by Spencer (1995, 2006, 2008; Spencer et al., 2006), a human vulnerability framework professes the 
alternative framing described. All humans have exposure to risks and protective factors, but the nature of the risks are different and the protective factors correlate with specifically experienced cultural supports and protective factors. Thus, the "bonus" of the PVEST conceptual strategy introduces the fact that individuals representing culturally diverse communities are protected or challenged by culturally specific opportunities or burdens. Present at any historical point in time are two types of research values or perspectives that contribute quite different insights into the policy: research and practice (e.g., as pedagogy) traditions. As simultaneously or overlapping subscribed to conceptual frames, these competing sets of research traditions and evaluative framings produce a conundrum. They not only posit and acknowledge significant imbalances when considering diverse humans' life experiences but also potentially introduce significant dissonance when 1560 M. B. Spencer and D. P. Swanson one reflects on the conduct of social science research, theorizing, funded programming, and everyday policyrelevant practice. As suggested, the unfounded assumption of Black self-hatred has long represented a theme in need of conceptual reformulation.

Challenges to youth development

In this section, major theories of identity development are utilized to illuminate the relationship between students' identity development and their academic performance, with focused acknowledgment of the extra challenges for students of color. Building on this framework, we highlight specific education policies and suggest the special impact they have had on adolescents' psychological well-being and development more broadly.

Under the most supportive conditions, biological, cognitive, and affective normative changes have the potential to enhance youth's vulnerability. This suggests that human vulnerability is the relationship between frequently unacknowledged risks and protective factors, which unmistakably matter given the obligation to confront and meet the life course requirements of developmental tasks (see Havighurst, 1953). Given the particularly salient tasks associated with adolescent identity formation, there are few points in the life course beyond adolescence when the invisible or unacknowledged fact and character of vulnerability have more dire implications. Erik Erikson was the first to describe human development across the entire life course and to focus on identity development as the defining characteristic of adolescence (Muuss, Velder, \& Porton, 1996).

Erikson (1950) explained that "psychosocial development proceeds by critical steps - "critical" being a characteristic of turning points, of moments of decision between progress and regression, integration and retardation" (pp. 270-271) and proposed eight distinct stages of development. Each stage is characterized by a conflict between two opposing forces of which the primary goal of development is the acquisition of ego identity. Stage 5, which occurs during adolescence, is defined by a conflict between identity and role confusion. Strategies by which adolescents resolve the identity conflict impact their development through the final stages from early to late adulthood. With the onset of puberty, adolescents are "primarily concerned with what they appear to be in the eyes of others compared with what they feel they are, and with the question of how to connect the roles and skills cultivated earlier with the occupational prototypes of the day" (p. 260). A sense of ego identity is accomplished when "inner sameness and continuity prepared in the past are matched by sameness and continuity of one's 
meaning for others" (p. 261). The danger of Stage 5 is role confusion, a state in which individuals temporarily over identify with peers held in high regard, and in doing so, seem to lose their own sense of identity. As a defense against role confusion, adolescents tend to be "clannish, and cruel in their exclusion of all those who are 'different,' in skin color" (Erikson, 1950, p. 262) and other arbitrary characteristics.

To further illuminate the complex processes experienced during Erikson's fifth stage, James Marcia $(1966,1980)$ described and empirically validated four distinct modes in which adolescents react to the identity crisis. The four modes differ along two variables: whether the subject has undergone a crisis and whether they have committed to a particular occupational, political, or religious ideology. Identity achievement individuals have experienced a crisis period in which they were forced to reevaluate their beliefs and have emerged from the crisis with a commitment to a particular identity. Foreclosure individuals have also committed to particular ideologies or occupations, but they have not experienced the crisis period. These individuals tend to exhibit identities that mirror those of their parents or other socializing adults. In contrast, moratorium individuals are actively engaged in the crisis period, meaning that they are exploring different paths and questioning belief systems. From moratorium, individuals may reach a point of commitment and identity achievement, or they may disengage themselves from the crisis without making a commitment, thus entering identity diffusion. The identity diffusion individuals are characterized by their lack of interest in committing to a professional, political, or religious path.

Identity achievement is a dynamic process, which means that an identity-achieved individual can regress to a state of moratorium many times over the life course; of course, this is exacerbated if the individual failed to achieve a modicum of success in resolving the Stage 5 identity-formation task at adolescence. When the environment changes and individuals are faced with dissonant value systems, they may return to a state of moratorium. At any point, the moratorium individual has the potential to become either identity achieved or identity diffused.

Of the four modes, identity achievement is associated with the highest self-esteem and greatest resilience in the face of negative feedback. It is important to avoid casting value judgments when comparing foreclosure and moratorium. Each may be adaptive, depending on social context and individual differences.

In addition to forming convictions regarding careers, religion, and politics as normative tasks toward productive citizenship, racial and ethnic minority youths must also adopt an identity congruent with their group membership that offers the foundation of group strengths in contrast to the stereotyped societal messages. Various models exist for explaining and assessing the relationship of these identity processes on youths outcomes (e.g., see Cross, 1991; Sellers, Smith, Shelton, Rowley, \& Chavous, 1998). Although there are differences in how the identity processes develop, there is consistency regarding the impact on viewing the world from a Eurocentric lens versus a secure racial and ethnic identity. The former situates youths for internalizing stereotypic messages, although the latter contributes to their engagement in diverse perspectives, without risking their own identity. Luthar and Latendresse (2002) describe maladaptive coping of privileged youngsters who lack adaptive coping practice opportunities. 
However, from a developmental science perspective, few studies examine privilege and commensurate identity processes in the case of White, middle-income youth.

Opportunities and challenges Identity and academic achievement

The academic achievement gap between students of different races and socioeconomic groups is a challenge that persists. In an oft-cited paper, Fordham and Ogbu (1986) explained the achievement gap between Blacks and Whites as the result of Black resistance to "acting White." They conclude that because of a history of oppression by the mainstream culture, African Americans reject the norms of that group, including academic ones.

This explanation does not hold true and has provoked much victim blaming. Our nation's history of oppression leaves no evidence of having diminished the achievement motivation of African Americans. Historically, African Americans show a level of achievement motivation that is unmatched (Spencer et al., 2003). Therefore, it may not then be necessarily a lack of motivation, but under acknowledged barriers presented in the form of structural racism that limit African American academic achievement and social mobility.

There are numerous identity-based explanations for the disparate achievement of racial groups. Among the most well-known is the concept of stereotype threat (Steele \& Aronson, 1995). Identity-achieved students are less likely to be affected by negative feedback than are students in foreclosure, moratorium, or identity diffusion (Marcia, 1966).

In a culture where African Americans, especially males, are often stereotyped as underachieving and potentially dangerous, low academic achievement may be a product of identities that have emerged from maladaptive coping mechanisms employed over time (Gordon \& Gordon, 1994; Spencer et al., 2004). In demoralized, urban schools, which are disproportionately attended by African American students, attention from peers and teachers may be more easily gained through displays of aggressive, hypermasculine behaviors than by investing oneself in schoolwork. If academic effort is not rewarded with positive feedback from teachers and peers, or if inadequate instruction means that academic effort is not realized in the form of grades and standardized test scores, then students are likely to disengage and find other means of gaining attention.

In distinct contrast to the idea that all students are only able to achieve academic success by "acting White" or assimilating to mainstream culture, empirical studies have shown that students who are able to traverse multiple worlds perform best academically (Phelan et al., 1991).It is important for students to achieve an identity that reflects and values their own individuality, including both assigned and chosen characteristics. However, the reality is that the majority of schools and teachers adhere to and reward behavior that fits into the mainstream mold. For many students, typically those from the White, middle class, there is not much difference in their world at school and at home (i.e., they experience "consonant" home-school matches as opposed to the "dissonance" frequently experienced by many minorities). However, for those students whose home life and friend groups are much different from the social norms at school, it is critical to learn the codes of multiple worlds. 
Various contexts can set up opportunities and situations for facilitating beliefs of privilege, opportunity, or exacerbated risk. Essed (2002) developed an understanding of racism that synthesizes the ways in which microaggression works in conjunction with and through systemic inequities. Essed defines "everyday racism" in a manner that aids an understanding of how vulnerability can function very differently between groups by noting its definition as:

"a process in which a). socialized racist notions are integrated into meanings that make practices immediately definable and manageable, b). practices with racist implications become in themselves familiar and repetitive, and c). underlying racial and ethnic relations are actualized and reinforced through these routine or familiar practices in everyday situations." (p. 190)"

Furthermore, everyday racism is not necessarily communicated through direct interactions with people of color. For example, journalists produce their everyday products that perpetuate racist discourse and policymakers produce programs that can inadvertently perpetuate inequities particularly given the 21stcentury social media and general communication options. Essed maintains that "when racist notions and actions infiltrate everyday life and become part of the reproduction of the system, the system reproduces everyday racism" (p. 188). Hence macro and micro (communication technology facilitated) forms of racism are extensions of one another, and microaggressions, although racist, are not always funded by intentional prejudice.

Omi and Winant (2002) refer to a "common sense" understanding, which they contend is a normative system of ideas and practices perpetuated through education, the media, policy, and so on. Similar to Essed's characterization of everyday racism, racial inequities are perpetuated through these common sense ways of relating and being in such a way that they are more insidiously woven into the fabric of society than are expressions of direct racial prejudice. However, the existence of this form of racism in society does not eliminate more direct forms of prejudice. Rather, Omi and Winant maintain that our understanding of racism has broadened such that we now understand it to exist through plural forms that function through diverse contexts and power dynamics. At the same time, we would add that excessive privileges and supports are "privileged" in the same way.

It is through the development of this normative system that hegemony operates. Hegemony defines the ways in which relations of power frame the shape of racism. The form of racism, as discussed previously in this review, is especially related to the historical and temporal academic context, including research and scholarly traditions and the positioning of each.

Power and positionality in research

In theorizing individuals' ability to resist and overcome oppression, Prilleltensky's (2008) view asserts that power is "never political or psychological; [but] always both" (p. 116). We 1562 M. B. Spencer and D. P. Swanson have positioned development within historical and sociopolitical factors to illuminate this point. These factors provide not only the context in which development occurs but also the one in which research is conducted. Elias, Gara, and Ubriaco (1985) presented several adaptive challenges common among students transitioning into a new school that are also relevant in considering other adaptive challenges particularly salient during adolescence. These include (a) making the necessary shifts in 
expected behaviors when engaging in new relationships within new contexts; (b) adapting to shifts in membership and positionality that result from the expectations or availability of support; (c) the reorganization of personal and social support resources to maximize one's psychological well-being; (d) reassessing, and if necessary, restructuring perception of contextual conditions as supportive or unfavorable; and (e) managing the dissonance and stress associated with uncertainties regarding expectations or one's capacity to effectively function within them. Research examining opportunities and challenges are positioned to address the differentially experienced impact of ill-conceptualized policies on youths' developmental outcomes. Unfortunately, when cultural traditions and patterns are considered and included in developmental and psychopathology research efforts (i.e., if acknowledged at all), explanatory references are made only to the individuals viewed as different from the assumed "standard" (i.e., White, middle-income, ordinarily male individuals).

When children enter school, they are confronted with myriad new socializing factors; the interpersonal interactions with peers and teachers impact and shape their identities. As new perspectives and diverse individuals are introduced, children begin to utilize stereotypes to categorize themselves and others (Spencer, 1984, 1985; Spencer \& Dornbush, 1990; Sullivan, 1953). They differentiate themselves from others and form groups, based on characteristics like skin color or personal interests. As children transition into adolescence, the scope of challenges increases owing to the cognitive shifts noted earlier; the changes allow for greater differentiation in meaning-making processes, and expanded contexts create challenges requiring adaptive responses. As suggested, all youth, however, have the potential for high psychological vulnerability and maladaptive coping, yet there are differences in the expression of vulnerability (Anthony, 1974; Luthar, Cicchetti, \& Becker, 2000; Swanson, 2010). Low risk environments and the insertion of significant support can mediate the expression of high vulnerability, whereas highrisk environments increase adaptive challenges and the probability of maladaptive outcomes.

As suggested, structural conditions linked to poverty, race, and ethnicity frequently result in unsupportive and high-risk environments. For many racial and ethnic minority youths, the developmental crises and stresses of this period frequently are compounded by unstable factors in their immediate context (Spencer, 2008; Swanson, 2010). Effective social and educational policies for poor and ethnic minority youth support greater resilience and reduce the likelihood of adverse outcomes by implementing changes relevant to the structural conditions. There has been an infusion of resources and investigations on mentoring youths as the single most common factor associated with meditating youth vulnerability, thus creating supportive environments. However, these are supportive relationships that occur in varied contexts with variable results (see Rodr'ıguez-Planas, 2012).

Often missing in research that has reduced resilience to mentoring as a primary factor is the acknowledgment of factors associated with attributes of the mentor and structural conditions that support the mentoring process. This implies two trajectories for research examining opportunities and challenges to developmental outcomes using resilience research as illustrative (Luthar et al., 2000; Phelan et al., 1991; Swanson, 2010). The first is to systematically examine structural conditions directly impacting areas known to support adaptive outcomes for youth. In essence, beyond the interpersonal, under what policy- and practice-based conditions are risks mediated? The second is to examine the impact of resilience on later developmental outcomes. In other words, what is the cost of resilience to 
development? Resilience is predicated on the presence of adversity and given normative human adaptive processes, the energy required to even feign stability potentially creates a strain on other areas supporting psychological well-being. Nevertheless, little is known regarding the extent to which resilience during adolescence might compromise consequent periods and areas of development. Conceptual perspectives have suggested the potential of some youths' resilience as "masking" risks (Spencer et al., 2008) or vulnerability that is stable versus reactive (Luthar et al., 2000). Phelan et al's (1991) study suggested the impact of negotiating difficult contextual and interpersonal boundaries on youth outcomes.

In essence, sociopolitical factors that shape the structural conditions and contexts in which development occurs should not be dismissed in conceptualizing factors contributing risk, vulnerability, and youth outcomes. Although investigators are not expected to be political analysts, there is a responsibility for positioning research studies and their findings by challenging patterned traditions of privilege that frame discussion around the complexities of development. In recent years, there have been increased advances in technology, methodology (i.e., mixed methods), and analytical strategies (i.e., growth mixture modeling and mediated-moderation modeling) for investigating developmental processes. However, the propensity for conducting innovative analyses can outweigh the necessity for research that draws on theoretical perspectives that are contextual and developmental framed.

Although attention has been devoted to discussing structural and developmental conditions in research, a particularly elusive challenge in conceptual and methodological considerations is that of unrecognized or unexamined biases held by investigators. One's personal values and experiences influence the type of behaviors and constructs identified as problems worthy of empirical investigation and the procedures used in exploring and interpreting their etiology and Opportunities and challenges trajectories. Although seeking objectivity in the design and implementation of research, an often ignored consideration is the investigator's philosophical assumptions regarding the population or the issue being examined and the position of power it affords when embedded in privilege. Research has maintained an enduring problemfocused perspective, even with questionable attention on positive youth development in which youth vulnerabilities are identified by their behavior. For example, youths with "at least one supportive adult" should not be exhibiting persistent behavior problems, unless there is something more pronounced wrong with the youth. Within the positive youth development research, there is more deliberate attention afforded the external assets that support outcomes. However, this research varies in its application to racial and ethnic minority youths (for an overview of positive youth development, see William, 2004).

A priori assumptions about etiologic and contributing factors can limit the conceptualization of influences inconsistent with the assumptions (see Swanson et al., 2002). For many years, for example, it has been difficult for investigators to acknowledge findings that parents' involvement in schools, which supported academic achievement, extended beyond the definition or requirement of being physically present at school-initiated meetings and activities. Other forms of involvement have frequently been dismissed. Even with recent research acknowledging the significance of diverse forms of parental involvement in students' academic performance, there is little value placed on the less traditional 
middle-class supported activities. Thus education research and school based policies and practices that reference parental involvement continue to reflect the long-standing traditional criteria and identify lack of parental involvement as a central problem in students' disengagement with school. It is assumed that an involved parent will be engaged with the student's teacher and serve as the liaison between the school's expectations and the student's progress. In essence, although parental involvement is the focus of presumed etiology, other factors, such as a welcoming school or the parent's work conflicts, are deemed less relevant. More fundamentally ignored, however, is an equally pejorative or bias-based perspective that parents are not actively involved in supporting their child's school experiences if they are never seen at the school. Although it is important for investigators to recognize and challenge their own assumptions, it is also important within policy arenas to question decidedly intuitive findings, suggestive of unexamined values or a priori assumptions.

Future research will draw from the advances made thus far in the field with regard to the interdisciplinarity of work and the continued focus on normative developmental processes. Given the foundation provided in these areas, we can begin to note, as part of research designs and published reports, divergent standards that frame the experiences relevant to participants. For example, noting the percentage of free lunch for schools is informative of the school's poverty level, but it is seldom reported with studies on suburban schools. Middle income minority children attend low-resource urban schools and working-class White children frequently attend suburban schools; however, the population heterogeneity is seldom acknowledged in the design of research and interpretation of findings. Similarly, household income is less informative than information about types of family assets. There is, in essence, a need to systematically and consistently examine structural conditions directly impacting areas known to support adaptive outcomes for youth. However, to reduce the influence of cloaked objectivity, exploring individuals' perceptions of structural conditions will illuminate areas for effective and sustainable support. This is fertile area for cross-disciplinary research that considers the developmental needs of children and youth.

The area of specific focus throughout this article has been on the limited acknowledgment of culture in research. There are significant variations in adaptations required given group and individual differences in challenges confronted and assets accessible. Patterns of adaptive responses required become cultural traditions. Although there has been greater acknowledgment of the heterogeneity within groups and a general appreciation for the impact of culture on group members (e.g., as stereotypes), this information is seldom represented in studies beyond a reporting of participants by group. Assumptions continue to be made regarding common interpretations of key constructs (e.g., support) across diverse groups. From a purely empirical perspective, reporting differences in measurement reliability by groups can confirm interpretations of findings or provide new insight relevant for continued exploration.

Another area drawing from advances in the field is in the expanded design of research studies. The burgeoning of mixed methods is certainly an opportunity to expand on the interdisciplinary work the field has seen in recent decades. However, it is an approach to research that is as contentious as it is promising. Because of its perceived promise, it is being cited in proposals and professional presentations that lack the conceptual breadth and methodological sophistication to address the research questions being explored. Mixed methods, however, does not equate to mixed bags; it should 
be a conceptually based approach to addressing complex research questions that could account for exolevel influences on youth experiences and adaptive strategies. It is particularly relevant for examining the dynamic and recursive associations between levels of the ecology in consideration of culture and context-linked systems. There are some recently funded studies utilizing interdisciplinary strengths to conduct mixed methods research that is culturally relevant. Given the premise of our assertion in this article, we are hopeful for more explicit examination of undergirding assumptions regarding the lived experiences of individuals and groups being studied than have historically been noted.

\section{Conclusion}

Our purpose in this paper was to demonstrate the continuing lack of appreciation for the normal growth processes and 1564 M. B. Spencer and D. P. Swanson achieved development among American children and youth in culturally diverse and socially constructed contexts. Considered post hoc, the dilemma was evident in the framing and content of the 1954 Brown v. Board of Education decision and persists too frequently today as a nonissue in regard to policy decisions and teacher training. The impact is further exacerbated by zero tolerance policies. There are significant repercussions for the conceptual omission. These consequences include the lack of ownership of structured contributors to unacknowledged beliefs of privilege and assumptions of superiority for some, as well as coping processes that represent resistance, including assumptions of minority status and inferiority, for others. The shortsightedness contributes to the underachievement of some youths and, at the same time, undermines our acknowledgment of the demonstrated resiliency of others. Particularly the latter shortsightedness (i.e., failure to understand what youths actually need to succeed with an authentic sense of self) undermines the design and content of intended "achievement supports" (i.e., as policy decisions). The implications for teacher training, contemporary discussions regarding reparations, and the design of resiliency enhancements continue as dire goals. Although our perspective continues to press for a paradigmatic shift, the opportunity to highlight considerations for conceptual innovations and inclusiveness suggests optimism for the future of the field. This is further supported by the wealth of interdisciplinary and developmentally focused research within the field that did not exist during prior periods.

References

Acosta, O. M., Weist, M. D., Lopez, F. A., Shafer, M. E., \& Pizarro, L. J. (2004). Assessing the psychosocial and academic needs of Latino youth to inform the development of school-based programs. Behavior Modification, 28, 579-595.

Advancement Project. (2010). Test, punish, and push out: How zero tolerance and high-stakes testing funnel youth into the school to prison pipeline. Washington DC: Author.

Advancement Project and the Civil Rights Project at Harvard University. (2000). Opportunities suspended: The devastating consequences of zero tolerance and school discipline. Paper presented at the National Summit on Zero Tolerance Report, Washington, DC, June 15-16. 
Allen, W. R., Spencer, M. B., \& Brookins, G. K. (1985). Synthesis: Black children keep on growing. In M. B. Spencer, G. K. Brookins, \& W. R. Allen (Eds.), Beginnings: The social and affective development of black children (pp. 301-314). Hillsdale, NJ: Erlbaum.

American Psychological Association (APA) Zero Tolerance Task Force. (2008). Are zero tolerance policies effective in the schools? An evidentiary review and recommendations. American Psychologist, 63, 852862.

Anthony, E. J. (1974). The syndrome of the psychologically invulnerable child. In E. J. Anthony \& C. Koupernik (Eds.), The child in his family: Vol. 3. Children at psychiatric risk (pp. 529-544). New York: Wiley.

Armour, J. D. (2000). Race ipsa loquitur: Of reasonable racists, intelligent Bayesians, and involuntary negrophobes. In R. Delgado \& J. Stefancic (Eds.), Critical race theory: The cutting edge (pp. 180-193). Philadelphia, PA: Temple University Press.

Bell, D. A.(2000). Serving two masters: Integration ideals and client interests in school desegregation litigation. In R. Delgado \& J. Stefancic (Eds.), Critical race theory: The cutting edge (pp. 236-246). Philadelphia, PA: Temple University Press.

Boccanfuso, C., \& Kuhfeld, M. (2011). Multiple responses, promising results: Evidence-based nonpunitive alternatives to zero tolerance. Child Trends Research Brief, 9, 1-12.

Bronfenbrenner, U. (2005). Ecological systems theory. In U. Bronfenbrenner (Ed.), Making human beings human: Bioecological perspectives on human development (pp. 106-173). Thousand Oaks, CA: Sage.

Bronfenbrenner, U., \& Crouter, A. C. (1983). The evolution of environmental models in developmental research. In P. H. Mussen (Series Ed.) \& P. H. Mussen (Vol. Ed.), Handbook of child psychology: Vol. 1. History, theory, methods (4th ed., pp. 357-414). New York: Wiley.

Bronwyn, E., \& Luthar, S. S. (2002). Social-emotional factors affecting achievement outcomes among disadvantaged students: Closing the achievement gap. Educational Psychologist, 37, 197-214. Brown v. Board of Education, 347 US 483 (1954).

Butler, P. (2000). Racially based jury nullification: Black power in the criminal justice system. In R. Delgado \& J. Stefancic (Eds.), Criticalrace theory: The cutting edge (pp. 194-203). Philadelphia, PA: Temple University Press.

Casella, R. (2003). Zero tolerance policy in schools: Rationale, consequences, and alternatives. Teachers College Record, 105, 872-892.

Chestang, L. W. (1972). Character formation in a hostile environment (Occasional Paper No. 3). Chicago: University of Chicago, School of Social Work Administration. Chin,J. K., Dowdy, E.,Jimerson, S. R., \& Rime, W.J. (2012). Alternativesto suspensions: Rationale and recommendations. Journal of School Violence, $11,156-173$. 
Cicchetti, D., \& Toth, S. L. (2009). The past achievements and future promises of developmental psychopathology: The coming of age of a discipline. Journal of Child Psychology and Psychiatry, 50, 1625.

Cross,W.E.(1991). Shades of black: Diversity in African American identity. Philadelphia, PA: Temple University Press.

Day-Vines, N. L., \& Day-Hairston, B. O. (2005). Culturally congruent strategies for addressing the behavioral needs of urban, African American male adolescents. Professional School Counseling, 8, 236243.

Delgado, R. (2009). Affirmative action as a majoritarian device: Or, do you really want to be a role model? In E. Taylor, D. Gillborn, \& G. Ladson Billings (Eds.), Foundations of critical race theory in education (pp. 109-116). New York: Routledge.

Du Bois, W. E. B. (1903). The souls of Black folk. New York: Dover.

Du Bois, W. E. B. (1935). Does the Negro need separate schools? Journal of Negro Education, 4, 328335.

Elder, G. H. (1998). The life course and human development. In R. M. Lerner (Ed.), Handbook of child psychology: Vol. 1. Theoretical models of human development (pp. 939-992). New York: Wiley.

Elias, M.J., Gara, M., \& Ubriaco, M. (1985). Sources ofstress and support in children's transition to middle school: An empirical analysis. Journal of Clinical Child Psychology, 14, 112-118.

Epps, E. G. (1985). Preface. In M. B. Spencer, G. K. Brookins, \& W.R. Allen (Eds.), Beginnings: The social and affective development of Black children. Hillsdale, NJ: Erlbaum.

Erikson, E. H. (1950). Childhood and society. New York: Norton. Erikson, E. H. (1968). Identity: Youth and crisis. New York: Norton.

Essed, P.(2002). Everyday racism: A new approach to the study of racism.In P.Essed\& D. T.Goldberg (Eds.), Race critical theories: Test and context (pp. 176-194). Malden, MA: Blackwell.

Fenning, P., \& Rose, J. (2007). Overrepresentation of African American students in exclusionary discipline: The role of school policy. Urban Education, 42, 536-559.

Fenning, P. A., Pulaski, S., Gomez, M., Morello, M., Maciel, L., Maroney, E., et al. (2012). Call to action: A critical need for designing alternatives to suspension and expulsion. Journal of School Violence, 11, 105117.

Fordham, S., \& Ogbu, J. U. (1986). Black students' school success: Coping with the "burden of 'acting White.'" Urban Review, 18, 176-206. 
Franklin, V. P. (1985). From integration to Black self-determination: Changing social science perspectives on Afro-American life and culture. In M. B. Spencer, G. K. Brookins, \& W. R. Allen (Eds.), Beginnings: The social and affective development of Black children ( pp. 19-28). Hillsdale, NJ: Erlbaum.

Garbarino, J. (1979). The role of the school in the human ecology of child maltreatment. School Review, 87, 190-213.

Gordon, T., \& Gordon, E. M. (1994). Pedagogical and contextual issues affecting African American males in school and society. Journal of Negro Education, 63, 508-531. Opportunities and challenges

Gregory, A., Cornell, D., \& Fan, X. (2011). The relationship of school structure and support to suspension ratesfor Black and White high school students. American Educational Research Journal, 48, 904-934.

Havighurst, R. J. (1953). Human development and education. New York: McKay.

Henault, C. (2001). Zero tolerance in schools. Journal of Lawand Education, 30, 447-453.

Howe, N., \& Strauss, W. (2000). Millennials rising: The next great generation. New York: Vintage Books. Johnson, A. M. Jr. (2000). Bid whist, tonk, and United States v. Fordice: Why integrationism fails AfricanAmericans again. In R. Delgado \& J. Stefancic (Eds.), Critical race theory: The cutting edge (pp. 404-415). Philadelphia, PA: Temple University Press.

Lewis, C. W., Butler, B. R., Bonner, I. I., Fred, A., \& Joubert, M. (2010). African American male discipline patterns and school district responses resulting impact on academic achievement: Implications for urban educators and policy makers. Journal of African American Malesin Education, 1, 7-25.

Luthar, S. S., Cichetti, D., \& Becker, B. (2000). The construct of resilience: A critical evaluation and guidelines for future work. Child Development, 71, 543-562.

Luthar, S. S., \& Latendresse, S. J. (2002). Adolescent risk: The cost of affluence. New Directions in Youth Development, 95, 101-121.

Marable, M. (1995). Affirmative action and the politics of race. Beyond Black and White: Rethinking race in American politics and society ( pp. 81-89) New York: Verso.

Marcia,J. E. (1966). Development and validation of ego identity status. Journal of Personality and Social Psychology, 3, 551-558.

Marcia,J. E. (1980). Identity in Adolescence. In J. Adelson (Ed.), Handbook of adolescent psychology (pp. 159-187). New York: Wiley. McIntosh, P. (1989, July-August). White privilege: Unpacking the invisible knapsack. Peace and Freedom, 10-12.

Michail, S. (2013). Understanding school responses to students' challenging behaviour: A review of literature. Improving Schools, 14, 156-171. 
Morris, E. J. (2012). Respect, protection, faith, and love: Major care constructs identified within the subculture of selected urban African American adolescent gang members. Journal of Transcultural Nursing, 23, 262-269.

Morrison, G. M., Anthony, S., Storino, M., Cheng,J., Furlong, M.J., \& Morrison, R. L. (2001). School expulsion as a process and as event: Before and after effects on children at-risk for school discipline. In R. J. Skiba \& G. G. Noam (Eds.), New directions in youth development-Zero tolerance: Can suspension and expulsion keep schools safe? (pp. 45-72). New York: Wiley.

Muuss, R. E. H., Velder, E., \& Porton, H. (1996). Theories of adolescence. New York: McGraw-Hill. Noguera, P. (2003). Schools, prisons, and social implications of punishment: Rethinking disciplinary practices. Theory into Practice, 42, 341-350.

Omi, M., \& Winant, H. (2002). Racial formation. In D. Goldberg \& P. Essed (Eds.), Race critical theories: Text and context (pp. 123-45). Oxford: Blackwell.

Phelan, P., Davidson, A. L., \& Cao, H. T. (1991). Students' multiple worlds: Negotiating the boundaries of family, peer, and school cultures. Anthropology \& Education Quarterly, 22, 224-250.

Prilleltensky, I. (2008). The role of powerin wellness, oppression, and liberation: The promise of psychopolitical validity. Journal of Community Psychology, 36, 116-136.

Raffaele Mendez, L. M., \& Knoff, H. M. (2003). Who gets suspended from school and why: A demographic analysis of schools and disciplinary infractions in a large school district. Education \& Treatment of Children, 26, 30-51.

Rodr'ıguez-Planas, N. (2012). Mentoring, educational services, and incentives to learn: What do we know about them? Evaluation and Program Planning, 35, 481-490.

Schulz, L. L., \& Rubel, D. J. (2011). A phenomenology of alienation in high school: The experiences of five male non-completers. Professional School Counseling, 14, 286-298.

Sellers, R. M., Smith, M., Shelton, J. N., Rowley, S. J., \& Chavous, T. M. (1998). Multidimensional model of racial identity: A reconceptualization of African American racial identity. Personality and Social Psychology Review, 2, 18-39.

Sharkey, J. D., \& Fenning, P. A. (2012). Rationale for designing school contexts in support of proactive discipline. Journal of School Violence, 11, 95-104.

Skiba, R. L., \& Peterson,R. (1999). The dark side of zero tolerance:Can punishment lead to safe schools. Phi Delta Kappan, 80, 372-382.

Skiba, R. J., Peterson, R., Boone, K, \& Fontanini, A. (2000). Preventing school violence: A practical guide to comprehensive planning. Reaching Today's Youth, 5, 58-62. 
Slaughter, D. T., \& McWorter, G. A. (1985). Social origins and early features of the scientific study of Black American families and children. In M. B. Spencer, G. K. Brookins, \& W. R. Allen (Eds.), Beginnings: The social and affective development of black children (pp. 5-18). Hillsdale, NJ: Erlbaum.

Spencer, M. B. (1984). Black children's race awareness, racial attitudes, and self concept: A reinterpretation. Journal of Child Psychology and Psychiatry, 25, 433-441.

Spencer, M. B. (1985). Cultural cognition and social cognition as identity factors in Black children's personal social growth. In M. B. Spencer, G. K. Brookins, \& W. R. Allen (Eds.), Beginnings: The social and affective development of Black children (pp. 215-230). Hillsdale, NJ: Erlbaum.

Spencer, M. B. (1995). Old issues and new theorizing about African American youth: A phenomenological variant of ecological systems theory. In R. L. Taylor (Ed.), African-American youth: Their social and economic status in the United States (pp. 37-69). Westport, CT: Praeger.

Spencer, M. B. (2006). Phenomenology and ecological systems theory: Development of diverse groups. In R. M. Lerner \& W. Damon (Eds.), Handbook of child psychology: Vol. 1. Theoretical models of human development (6th ed., pp. 829-893). Hoboken, NJ: Wiley.

Spencer, M. B. (2008). Phenomenology and ecological systems theory: Development of diverse groups. In W. Damon \& R. M. Lerner (Eds.), Child and adolescent development: An advanced course (pp. 696735). Hoboken, NJ: Wiley.

Spencer, M. B., Brookins, G. K., \& Allen, W. R. (Eds.). (1985). Beginnings: Social and affective development of Black children. Hillsdale, NJ: Erlbaum.

Spencer, M. B., Cross, W. E., Harpalani, V., \& Goss, T. N. (2003). Historical and developmental perspectives on Black academic achievement: Debunking the "acting White" myth and posing new directions for research. In C. C. Yeakey \& R. D. Henderson (Eds.), Surmounting all odds: Education, opportunity and society in the new millennium (pp. 273-304). Greenwich, CT: Information Age.

Spencer, M. B., \& Dornbusch, S. (1990). Challenges in studying minority youth. In S. Feldman \& G. Elliot (Eds.), At the threshold: The developing adolescent (pp. 123-146). Cambridge, MA: Harvard University Press.

Spencer, M. B., Fegley, S. G., Harpalani, V., \& Seaton, G. (2004). Understanding hypermasculinity in context: A theory-driven analysis of urban adolescent males' coping responses. Research in Human Development, 1, 229-257.

Spencer, M. B., Harpalani, V., Cassidy, E., Jacobs, C., Donde, S., Goss, T. N., et al. (2006). Understanding vulnerability and resilience from a normative development perspective: Implications for racially and ethnically diverse youth. In D. Cicchetti \& D. J. Cohen (Eds.), Handbook of developmental psychopathology: Vol. 1. Theory and method (2nd ed., pp. 627-672). Hoboken, NJ: Wiley. 
Spencer, M. B., Harpalani, V., Fegley, S., Dell'Angelo, T., \& Seaton, G. (2002). Identity, self, and peers in context: A culturally-sensitive, developmental framework for analysis. In R. M. Lerner, F.Jacobs, \& D. Wertlieb (Eds.), Handbook of applied developmental science: Promoting positive child, adolescent, and family development through research, policies, and programs (Vol. 1, pp. 123-142). Thousand Oaks, CA. Sage.

Spencer, M. B., \& Jones-Walker, C. (2004). Interventions and services offered to former juvenile offenders reentering their communities: An analysis of program effectiveness. Youth Violence and Juvenile Justice, 2, 88-97.

Spencer, M. B., Swanson, D. P., \& Edwards, M. (2010). Sociopolitical contexts of development. In D. P. Swanson, M. Edwards, \& M. B. Spencer (Eds.), Adolescence: Development during a global era (pp. 1-27). Waltham, MA: Academic Press.

Spencer, M. B., Tinsley, B., Dupree, D., \& Fegley, S. (2012). Maximizing cultural and contextuallysensitive assessment strategies in developmental and educational research. In W. Tate \& C. Yeakey (Eds.), Research on schools, neighborhoods and communities: Toward civic responsibility (pp. 299-326). Washington, DC: American Education Research Association.

Sroufe, L. A. (1989). Pathways to adaptation and maladaptation: Psychopathology as developmental deviation. In D. Cicchetti (Ed.), Rochester 1566 M. B. Spencer and D. P. Swanson symposia on developmental psychopathology: The emergence of a discipline (Vol. 1, pp. 13-40). Hillsdale, NJ: Erlbaum.

Sroufe, L. A. (2007). The place of development in developmental psychopathology. In A. S. Masten (Ed.), Multilevel dynamics in developmental psychopathology: The Minnesota Symposia on Child Psychology (Vol. 34, pp. 285-299).

Mahwah, NJ: Erlbaum. Steele, C. M., \& Aronson,J. (1995). Stereotype threat and the intellectual test performance of African Americans. Journal of Personality and Social Psychology, 69, 797-811.

Stevenson, H. S. (1997). Missed, dissed and pissed: Making meaning of neighborhood risk, fear, and anger management in urban Black youth. Cultural Diversity and Mental Health, 3, 37-52.

Sullivan, H. S. (1953). The interpersonal theory of psychiatry. New York: Norton. Swanson, D. P. (2010). Psychosocial development: Identity, stress and competence.In D. P. Swanson, M. C. Edwards, \& M.B. Spencer (Eds.), Adolescence: Development in a global era (pp. 93-121). Boston: Elsevier.

Swanson, D. P., Spencer, M. B., Dell'Angelo, T., Harpalani, V., \& Spencer, T.(2002).Identity processes and the positive youth development of African Americans: An explanatory framework. In C. S. Taylor, R. M. Lerner, \& A. von Eye (Eds.), New directionsfor youth development: Theory, practice and research (Vol. 95, pp. 73-99). San Francisco, CA: Jossey- Bass.

Tobin, T., Sugai, G., \& Colvin, G. (1996). Patterns in middle school discipline records. Journal of Emotional and Behavioral Disorders, 4, 82-94. United States v. Fordice, 505 US 717 (1992). 
Van Acker, R. (2007). Antisocial, aggressive, and violent behavior in children and adolescents within alternative education settings: Prevention and intervention. Preventing School Failure: Alternative Education for Children and Youth, 51, 5-12.

Vavrus, F., \& Cole, K. (2002). I didn't do nothin: The discursive construction of school suspension. Urban Review, 34, 87-111.

Wallace, J. M., Goodkind, S., Wallace, C., \& Bachman, J. G. (2008). Racial, ethnic, and gender differences in school discipline among U.S. high school students: 1991-2005. Negro Education Review, 59, 47-62.

Ward, J. V. (1995). Cultivating a morality of care in African American adolescents: A culture-based model of violence prevention. Harvard Educational Review, 65, 175-188.

William, D. (2004). What is positive youth development? Annals of the American Academy of Political and Social Science, 591, 13-24. 